\section{Disodium 5-Cyanoisothiazoledithiolate as a Starting Material for Preparation of New Conductive Solids}

G. C. Papavassiliou*, G. A. Mousdis, V. Gionis, J. S. Zambounis, and S. Y. Yiannopoulos

Theoretical and Physical Chemistry Institute, National Hellenic Research Foundation, 48, Vassileos Constantinou Ave., Athens 116/35, Greece

Z. Naturforsch. 42b, 1050-1051 (1987); received March 23, 1987

Heterocycles, Metal 1,2-Dithiolenes, Tetrathiafulvalenes

Starting from disodium 5-cyanoisothiazoledithiolate some new substituted derivatives of the tetrathiafulvalene and some metal 1,2-dithiolenes with at least an isothiazolo-ring have been prepared. From these compounds a number of conductive cation radical salts have been obtained.

Substituted derivatives of tetrathiafulvalene having at least one pyrazino ring [1] or one pyridino ring [2] and metal 1,2-dithiolenes with pyrazino rings
$[1,3]$ or pyridino rings [4] have been reported recently.

In this paper we report the preparation of some derivatives of the tetrathiafulvalene having at least one isothiazolo ring, some metal 1,2-dithiolenes having two isothiazolo rings and a few of their cation radical salts. The new compounds were prepared from disodium 5-cyanoisothiazoledithiolate [5], as starting material, according to the following Scheme 1 .

\section{Experimental}

Disodium 5-cyanoisothiazoledithiolate (1) was transformed to the corresponding 1,3-dithiole-2thione (2a) or 1,3-dithiole-2-one (2b), after treatment with $\mathrm{Cl}_{2} \mathrm{CS}$ or $\mathrm{Cl}_{2} \mathrm{CO}$ in benzene, respectively, by well known procedures [6]. $\mathbf{2 b}$ can be also obtained from $\mathbf{2}$ a after treatment with $\mathrm{Hg}(\mathrm{OAc})_{2}$ in a mixture of $\mathrm{CH}_{3} \mathrm{COOH}$ and $\mathrm{CH}_{2} \mathrm{Cl}_{2}$ (1:1) [7]. Selfcoupling of $\mathbf{2 a}$ or $\mathbf{2 b}$ and cross-coupling of $\mathbf{2 b}$ with $\mathbf{4}$ [8] via triethyl phosphite at $120^{\circ} \mathrm{C}$ for $0.5-1 \mathrm{~h}$, afforded the bis(cyanoisothiazole)tetrathiafulvalene (3) and a mixture of $\mathbf{3}, \mathbf{5}$ and $\mathbf{5}^{\prime}$, respectively. The unsymmetrical tetrathiafulvalene (5) was separated from the mixture using silica gel column chromatog-
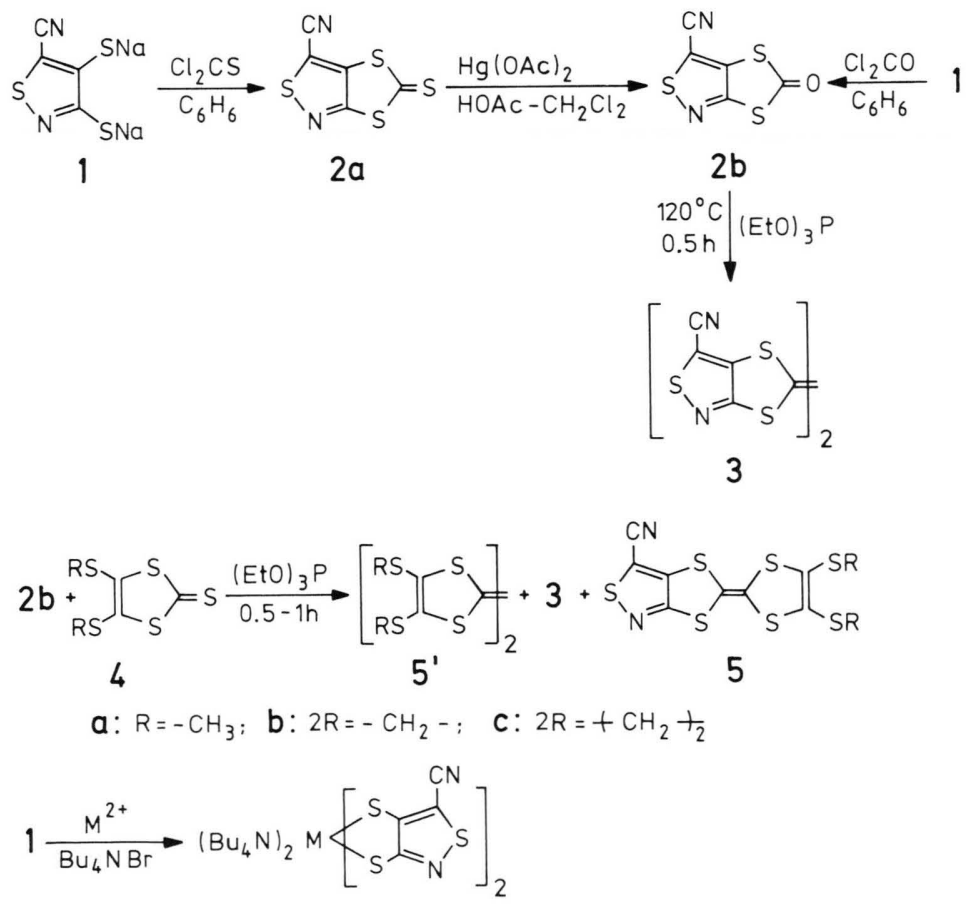

6

Scheme 1. $\quad a: M=Z n ; b: M=N i ; c: M=P d ; d: M=P t$

* Reprint requests to Dr. G. C. Papavassiliou.
Verlag der Zeitschrift für Naturforschung, D-7400 Tübingen 0932-0776/87/0800-1050/\$ 01.00/0 
Table I. Preparative and UV-spectral data.

\begin{tabular}{|c|c|c|c|c|c|c|c|c|}
\hline Compound & Yield [\%] & m.p. $\left[{ }^{\circ} \mathrm{C}\right]$ & Colour & $\begin{array}{l}\text { Analysis }[\%]^{*} \\
\text { C }\end{array}$ & $\mathrm{H}$ & $\mathrm{N}$ & $\mathrm{S}$ & $\begin{array}{l}\text { UV-spectrum } \\
{[\lambda / \mathrm{nm}]^{* *}}\end{array}$ \\
\hline l & 50 & $\begin{array}{l}300 \\
(\text { lit. 172-178)[5] }\end{array}$ & yellow & + & + & + & + & 396 \\
\hline $2 \mathbf{a}$ & 85 & 147 & yellow & $27.94(27.76)$ & $00(000)$ & $12.51(12.95)$ & $59.29(59.29)$ & 371 \\
\hline b & 70 & 110 & white & + & + & + & + & $310-318$ \\
\hline 3 & 52 & $>300$ & yellow & $32.17(32.60)$ & $00(000)$ & $15.13(15.21)$ & $52.04(52.17)$ & 400 \\
\hline c & 10 & 247 & orange-red & $31.84(31.91)$ & $1.08(1.06)$ & $7.42(7.44)$ & $59.43(59.57)$ & 434 \\
\hline $\mathbf{a}$ & 63 & 136 & yellow & $55.33(55.46)$ & $8.34(8.32)$ & $6.43(6.47)$ & $22.03(22.19)$ & $375-389$ \\
\hline b & 80 & 170 & brown-golden & $54.09(54.09)$ & $8.13(8.17)$ & $9.67(9.46)$ & $22.01(21.66)$ & $466-503$ \\
\hline c & 41 & 171 & brown & $52.84(52.96)$ & $7.80(7.94)$ & $6.16(6.18)$ & $22.03(21.18)$ & $433-448$ \\
\hline d & 45 & 168 & brown-golden & $48.11(48.24)$ & $7.07(7.23)$ & $5.60(5.63)$ & $19.18(19.29)$ & $474-502$ \\
\hline
\end{tabular}

* Calculated values are given in parentheses; ${ }^{* *}$ position of the low frequency band (solvent: $\mathrm{CH}_{3} \mathrm{CN}$ ); ${ }^{+}$this elementanalysis was not done.

raphy with $\mathrm{CH}_{2} \mathrm{Cl}_{2}$ as eluent solvent. Treatment of $\mathbf{1}$ with salts of transition metals $\mathrm{M}(=\mathrm{Zn}, \mathrm{Ni}, \mathrm{Pd}, \mathrm{Pt})$, by well known procedures [9], in a mixture of ethanol and water $1: 1$ and in presence of tetra- $n$-butylammonium bromide $\left(\mathrm{Bu}_{4} \mathrm{NBr}\right)$, afforded the corresponding $\left(\mathrm{Bu}_{4} \mathrm{~N}\right)_{2} \mathrm{M}(\text { dcit })_{2}$ [where $\mathrm{H}_{2}$ dcit $=3,4$-dimercapto-5-cyanoisothiazole] complexes (6). The compounds $\mathbf{2 a}, \mathbf{2} \mathbf{b}$ and $\mathbf{6 b}$ can be also prepared from compound 6a after treatment with $\mathrm{Cl}_{2} \mathrm{CS}, \mathrm{Cl}_{2} \mathrm{CO}$, and $\mathrm{NiCl}_{2}$, respectively. Preparative and $\mathrm{UV}$ spectral data are given in Table I.

The compounds $\mathbf{5 a}, \mathbf{5 b}$ and $\mathbf{5} \mathbf{c}$ gave brown precipitates of the type $(6) \mathrm{Br}_{3}$, after reaction with $\mathrm{Br}_{2}$ in $\mathrm{CH}_{2} \mathrm{Cl}_{2}$. Electrooxidation of $\mathbf{6 b}, \mathbf{6} \mathbf{c}$ and $\mathbf{6 d}$ in $\mathrm{CH}_{2} \mathrm{Cl}_{2}$ gave the corresponding cation deficient compounds of the type $\left(\mathrm{Bu}_{4} \mathrm{~N}\right)_{x} \mathrm{M}(\mathrm{dcit})_{2}$ (where $\left.0<x<1\right)$. However, electrooxidation of $\mathbf{6 b}, \mathbf{6 c}$ and $\mathbf{6 d}$, in $\mathrm{CH}_{2} \mathrm{Cl}_{2}$ and in the presence of a donor such as tetrathiafulvalene (TTF), bis(ethylenedithio)tetrathiafulvalene (BEDTTTF) (5'c), afforded a number of complexes with a composition $1: 1$.

\section{Results and Discussion}

Dc-conductivity $(\sigma)$ measurements on compressed polycrystalline pellets of the compounds $(\mathbf{6}) \mathrm{Br}_{3}$ and $\left(\mathrm{Bu}_{4} \mathrm{~N}\right)_{x} \mathrm{M}(\mathrm{dcit})_{2}$ showed that the former are semiconductors $\left(\sigma \sim 10^{-3} \Omega^{-1} \mathrm{~cm}^{-1}\right)$ and the latter are insulators. Similar measurements on compressed pellets of (TTF)M(dcit) $)_{2}$ and (BEDTTTF)M(dcit $)_{2}$ showed that these compounds are conductive with $\sigma$ of the order $1-30 \Omega^{-1} \mathrm{~cm}^{-1}$. The behaviour of these last materials is similar to that observed from materials with the same $\pi$-donors and similar metal 1,2 dithiolenes [10-13]. Materials containing $\mathrm{Ni}(\mathrm{dmit})_{2}$ [where $\mathrm{H}_{2}$ dmit is dimercaptoisotrithiocarbonate] have been found to be conductive solids in two or three dimensions $[11,12]$ because of the $\mathrm{S}-\mathrm{S}$ intermolecular contacts. In the present case both $\mathrm{S}-\mathrm{S}$ and $\mathrm{S}-\mathrm{N}$ contacts are expected. However, more accurate measurements are required on single crystals of these compounds. Also, it is expected that the compounds 3 and 5 will become better $\pi$-donors after substitution of $\mathrm{CN}$-group by hydrogen.
[1] G. C. Papavassiliou, S. Y. Yiannopoulos, and J. S. Zambounis, Mol. Cryst. Liq. Cryst. 120, 333 (1985); J. Chem. Soc. Chem. Commun. 1986, 820; Chem. Scripta 27, in press (1987).

[2] G. C. Papavassiliou, Chim. Chron. (New Series) 15, 161 (1987).

[3] J. Becher, C. E. Stidsen, H. Toftund, and F. M. Assad, Inorg. Chim. Acta 121, 23 (1986).

[4] M. N. Edinberry, G. E. Gymer, and S. Jevons, Brit. UK Pat. Appl. 2,053,189, Febr. 4, 1981; C. A. 95, 80748 z (1981).

[5] S. A. Vladuchick, T. Fukunaga, H. E. Simmons, and O. W. Webster, J. Org. Chem. 45, 5122 (1980).

[6] See for example E. Klingsberg, J. Am. Soc. 86, 5290 (1964); K. Dickoré, K. Sasse, and R. Wegler, Belg. Pat. 610,601, May 22, 1962; C. A. 57, 13774 h (1962).
[7] See for example K. Inoue, Y. Tasaka, O. Yamazaki, T. Nogami, and H. Mikawa, Chem. Lett. 1986, 781.

[8] G. C. Papavassiliou, J. S. Zambounis, and S. Y. Yiannopoulos, Chem. Scripta 27, in press (1987) and refs cited therein.

[9] See for example J. A. McCleverty, Progr. Inorg. Chem. 10, 49 (1986).

[10] G. C. Papavassiliou, Z. Naturforsch. 36b, 1200 (1981).

[11] H. Kobayashi, R. Kato, A. Kobayashi, and Y. Sasaki, Chem. Lett. 1985, 191; 1985, 535 .

[12] R. Kato, H. Kobayashi, A. Kobayashi, and Y. Sasaki, Chem. Lett. 1985, 131.

[13] L. Alcacer and H. Novais, in J. S. Miller (ed.): Extended Linear Chain Compounds, Plenum, New York-London 3, 319 (1983). 